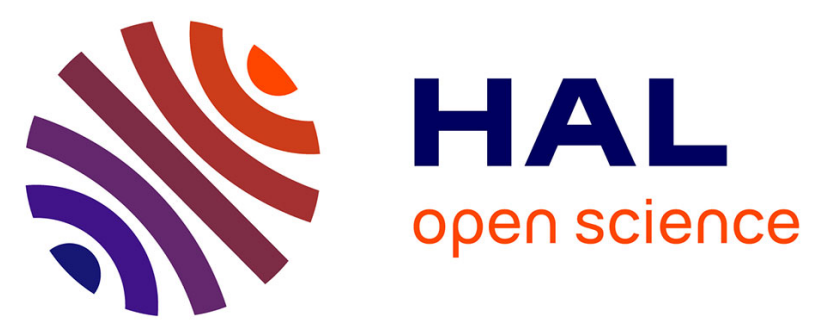

\title{
Pulmonary Arterial Histologic Lesions in Patients With COPD With Severe Pulmonary Hypertension
}

\author{
Vincent Bunel, Alice Guyard, Gaëlle Dauriat, Claire Danel, David Montani, \\ Clément Gauvain, Gabriel Thabut, Marc Humbert, Yves Castier, Peter \\ Dorfmüller, et al.
}

\section{To cite this version:}

Vincent Bunel, Alice Guyard, Gaëlle Dauriat, Claire Danel, David Montani, et al.. Pulmonary Arterial Histologic Lesions in Patients With COPD With Severe Pulmonary Hypertension. Chest, 2019, 156, pp.33 - 44. 10.1016/j.chest.2019.02.333 . hal-03488171

\section{HAL Id: hal-03488171 https://hal.science/hal-03488171}

Submitted on 20 Dec 2021

HAL is a multi-disciplinary open access archive for the deposit and dissemination of scientific research documents, whether they are published or not. The documents may come from teaching and research institutions in France or abroad, or from public or private research centers.
L'archive ouverte pluridisciplinaire HAL, est destinée au dépôt et à la diffusion de documents scientifiques de niveau recherche, publiés ou non, émanant des établissements d'enseignement et de recherche français ou étrangers, des laboratoires publics ou privés.

\section{(c) (1) $\$$}

Distributed under a Creative Commons Attribution - NonCommerciall 4.0 International 


\title{
PULMONARY ARTERIAL HISTOLOGICAL LESIONS IN COPD PATIENTS WITH SEVERE PULMONARY HYPERTENSION
}

\section{Pulmonary arterial pathology in severe PH-COPD}

\author{
Vincent Bunel ${ }^{1,2}$, Alice Guyard ${ }^{3}$, Gaëlle Dauriat ${ }^{1}$, Claire Danel $^{2,3}$, David Montani ${ }^{5}$, \\ Clément Gauvain $^{2}$, Gabriel Thabut ${ }^{1,2}$, Marc Humbert ${ }^{5}$, Yves Castier $^{6}$, \\ Peter Dorfmüller ${ }^{4,5 *}$ and Hervé Mal ${ }^{1,2}{ }^{*}$
}

\footnotetext{
${ }^{1}$ Service de Pneumologie B et Transplantation Pulmonaire, Université Paris 7 Denis Diderot, Hôpital Bichat, Paris, France

2 INSERM U1152, Département Hospitalo-Universitaire FIRE, Laboratoire d'Excellence INFLAMEX, Université Paris 7 Denis Diderot, Paris, France

${ }^{3}$ Département de Pathologie, Hôpital Bichat, Assistance Publique-Hôpitaux de Paris, Paris, France

${ }^{4}$ Service d'Anatomie Pathologique, Hôpital Marie Lannelongue, Le Plessis-Robinson, France ${ }^{5}$ Université Paris-Sud, AP-HP, Service de Pneumologie, Centre de Référence de I'Hypertension Pulmonaire Sévère, INSERM UMR_S 999,, Hôpital de Bicêtre, Le Kremlin Bicêtre, Paris, France ;

${ }^{6}$ Service de Chirurgie Thoracique et Vasculaire, Hôpital Bichat, Assistance PubliqueHôpitaux de Paris, Paris, France
}

*Both authors contributed equally to this work.

The authors have no conflict of interest regarding this manuscript to declare

\section{Address for correspondence:}

Hervé Mal, Service de Pneumologie B et Transplantation Pulmonaire, Hôpital Bichat, 46 rue Henri Huchard, Paris 75018, France.

E-mail: herve.mal@bch.aphp.fr 


\section{Abbreviations list}

PH: pulmonary hypertension; COPD: chronic obstructive pulmonary disease; mPAP: mean pulmonary pressure; $A A T$ : $\alpha 1$-antitrypsin; $\mathrm{FEV}_{1}$ : Forced expiratory volume in 1 sec; FVC: forced vital capacity; TLC: total lung capacity; VR: residual volume; DLCO: Diffusing capacity for carbon monoxide; Pw: pulmonary arterial wedge pressure;

BMI: body mass index; AAT: alpha-1 antitrypsin; RHC: right heart catheterization; PY: pack-years; LTOT: long-term oxygen therapy; NIV: non-invasive ventilation; Tx: transplantation; mMRC: modified medical research council dyspnea scale; VTED: venous thromboembolic disease; LVRS: lung volume reduction surgery; $\mathrm{PoH}$ : portal hypertension; OSA: obstructive sleep apnea; HIV: human immunodeficiency virus, LHF: left heart failure; IQR: interquartile range; $\mathrm{PaO}_{2}: \mathrm{O}_{2}$ arterial pressure on room air; $\mathrm{PaCO}_{2}: \mathrm{CO}_{2}$ arterial pressure on room air; 6' WT: 6-minute walk test; 6' WT $\triangle \mathrm{SpO}_{2}$ : Desaturation during the 6-minute walk test, pred: predicted; sPAP: systolic pulmonary arterial pressure; dPAP: diastolic pulmonary arterial pressure; $\mathrm{CO}$ : cardiac output; $\mathrm{Cl}$ : cardiac Index; PVR: pulmonary vascular resistance; IPVR: indexed pulmonary vascular resistance; WU: Wood units; 


\section{Abstract}

\section{Background}

The development of pulmonary hypertension $(\mathrm{PH})$ during the course of chronic obstructive pulmonary disease (COPD) is a well-known phenomenon, the prevalence depending on the severity of airway obstruction. When mean pulmonary pressure (mPAP) level at rest is $\geq 35 \mathrm{~mm} \mathrm{Hg}$ or $\geq 25 \mathrm{~mm} \mathrm{Hg}$ with low cardiac index, the term severe pulmonary hypertension has been chosen. For these patients, little is known on the underlying histological lesions. Our objective was to describe these lesions.

\section{Methods}

From the explants of patients undergoing lung transplantation, we compared retrospectively 3 groups of COPD patients: severe PH-COPD $(n=10)$, moderate PHCOPD (mPAP between 25 and $34 \mathrm{~mm} \mathrm{Hg}$ without low cardiac index) ( $\mathrm{n}=10$ ), no PH (mPAP $<25 \mathrm{~mm} \mathrm{Hg})(\mathrm{n}=10)$. Histological analysis of the explanted lungs examined the wall of medium-size arteries, the remodelling of microvessels and the pulmonary capillary density using morphometric measurements performed on 3 sections per patient.

\section{Results}

As compared with the moderate $\mathrm{PH}$ group, the remodelling score of the microvessels was significantly higher $(p=0.0045)$, and the capillary density was lower $(p=0.0049)$ in the severe PH-COPD group. The alterations of the medium-size arteries, important in group $1 \mathrm{PH}$, seemed less discriminating. 


\section{Conclusion}

The patients with severe PH-COPD appear to have a specific histological pattern, different from that observed in COPD patients with moderate $\mathrm{PH}$ or without $\mathrm{PH}$. 


\section{Introduction}

The development of pulmonary hypertension $(\mathrm{PH})$ during the course of chronic obstructive pulmonary disease (COPD) is a well-known phenomenon, the prevalence depending on the severity of airflow limitation. According to the classification of the $5^{\text {th }}$ world symposium on $\mathrm{PH}, \mathrm{PH}$ in this setting is classified as group $3 \mathrm{PH}(\mathrm{PH}$ due to chronic lung diseases and/or hypoxia) (1). When present in a COPD patient, $\mathrm{PH}$ is characterized in most cases by its slow progression, a mean pulmonary artery pressure (mPAP) ranging between 25 and $35 \mathrm{~mm} \mathrm{Hg}$ with preserved cardiac output, a rise of MPAP at exercise and during exacerbation of the disease, and a proven impact on survival (2-6). Beside this usual profile, a distinct hemodynamic phenotype with severe $\mathrm{PH}$ (severe PH-COPD) has been identified in a minority of COPD patients (7-9). Severe PH-COPD which is empirically defined as mPAP $\geq 35 \mathrm{~mm} \mathrm{Hg}$ or mPAP $\geq 25 \mathrm{~mm} \mathrm{Hg}$ with low cardiac index $\left(<2 \mathrm{~L} / \mathrm{min} / \mathrm{m}^{2}\right)(10)$ has been shown to be associated with markedly reduced DLCO and severe hypoxemia and seems to carry a poor prognosis. In this phenotype of COPD patients with particular involvement of the pulmonary circulation, little is known on the underlying pulmonary arterial lesions. Carlsen and coworkers have studied on explanted lungs the pathological lesions of pulmonary vessels according to the severity of $\mathrm{PH}$ and have shown that the extent of pulmonary vascular lesions correlated with the severity of PH (11). Some patients with severe $\mathrm{PH}-\mathrm{COPD}$ had lesions similar to those characteristic of idiopathic pulmonary arterial hypertension (PAH) (11). The aim of the present study based on a retrospective morphometric histological analysis of explanted lungs is to characterize the pulmonary arterial lesions of patients with severe PH-COPD and compare them with those observed in patients without $\mathrm{PH}$ and in patients with moderate $\mathrm{PH}$. 


\section{Materials and Methods}

Study population

We considered all patients with COPD or a1-antitrypsin (AAT) deficiency, who underwent lung transplantation between March 1988 and June 2013, in the Department of Pneumology B and Lung Transplantation, Bichat Hospital, Paris, France.

Our pretransplant evaluation program includes a right heart catheterization performed on a systematic basis, allowing us a precise measurement of mPAP.

In order to exclude a postcapillary component of $\mathrm{PH}$, we first discarded the cases where pulmonary artery wedge pressure $(\mathrm{Pw})$ was found $>15 \mathrm{~mm} \mathrm{Hg}$. All the cases of severe PH-COPD defined by $\mathrm{mPAP} \geq 35 \mathrm{~mm} \mathrm{Hg}$ or $\mathrm{mPAP} \geq 25 \mathrm{~mm} \mathrm{Hg}$ with low cardiac index $\left(<2 \mathrm{~L} / \mathrm{min} / \mathrm{m}^{2}\right)(10)$ were then retrieved (severe $\mathrm{PH}$-COPD group). This group was compared with 2 groups of an equal number of patients selected from the remaining cohort: a group of patients with moderate $\mathrm{PH}$ defined as $\mathrm{mPAP} \geq 25 \mathrm{~mm}$ $\mathrm{Hg}$ and $<35 \mathrm{~mm} \mathrm{Hg}$ without low cardiac index (moderate $\mathrm{PH}$ group) and a group of patients without $\mathrm{PH}$ (mPAP $<25 \mathrm{~mm} \mathrm{Hg}$ ) (no-PH group). The process of selection of the patients from the 2 latter groups was as follows: first, the patients were matched with those of the severe PH-COPD group according to smoking status (minimal difference in pack-years), age ( \pm 5 years), and presence or absence of AAT deficiency; second, the patients were randomly chosen for inclusion in each group.

\section{Characteristics of the patients}

For the selected patients, we retrieved from the files of the patients the following data, obtained at the pretransplant evaluation: demographics, medical data (medical and surgical history, smoking status, AAT deficiency when present), results of 
pulmonary function tests, blood gas analysis on room air, 6 minute-walk test (on room air or under oxygen if necessary), and right heart catheterization.

Forced expiratory volume in $1 \mathrm{sec}\left(\mathrm{FEV}_{1}\right)$ and lung volumes were measured by spirometry and plethysmography [forced vital capacity (FVC), total lung capacity (TLC), residual volume $(R V)$ ], all expressed in $L$ and percentage of predicted value. Diffusing capacity for carbon monoxide (DLCO) was expressed as percentage of predicted value.

Right heart catheterization data were obtained using a Swan-Ganz catheter, at rest, in supine position. Right atrial pressure, systolic/diastolic/mean pulmonary arterial pressure and pulmonary arterial wedge pressure $(\mathrm{Pw})$ were measured at the end of expiration. Cardiac output and cardiac index were calculated by thermodilution.

\section{$\underline{\text { Histological sample selection }}$}

For each transplanted patient, we selected 3 paraffin-embedded samples from the explanted lungs, stored in the department of pathology of our institution. All samples were obtained from the distal lung parenchyma (defined by the presence of a pleural border) and comprised (i) the upper lobe or culmen, (ii) the middle lobe (or lingula), and (iii) the lower lobe. For each sample, the following stainings were/had been performed: (1) Hematoxylin-Eosin-Saffron (HES) staining; (2) Orcein staining, specific of elastic fibers; (3) immunohistochemichal staining with an anti-actin antibody, marking the muscle cells; (4) immunohistochemichal staining with an antiERG antibody, marking the nuclei of endothelial cells (12). The analysis focused mostly on the right lung, unless a left single lung transplantation was performed or a patent abnormality was present on the right lung (e.g. tuberculosis sequelae). 


\section{$\underline{\text { Immunohistochemistry }}$}

Immunohistochemistry experiments were performed on paraffin-embedded lung samples: $4 \mu \mathrm{m}$ sections were dewaxed and rehydrated progressively. EDTA buffer ( $\mathrm{pH}$ 9.0) or Citrate buffer ( $\mathrm{pH} \mathrm{6.0)} \mathrm{were} \mathrm{used} \mathrm{for} \mathrm{antigen} \mathrm{retrieval} \mathrm{and} \mathrm{endogenous}$ peroxidase was quenched with hydrogen peroxide. Sections were blocked with $5 \%$ bovine serum albumin and incubated for 32 minutes with polyclonal antibody against actin (MS-113-P0), as recommended by the manufacturer (ThermoScientific, Cheshire, UK) or against Erg (MSK090-05), as recommended by the manufacturer (Zytomed Systems, Berlin, Germany). After incubation with a biotinylated secondary antibody, its detection was performed with HRP-streptavidine and DAB-solution.

\section{Histological analysis}

We analyzed three elements of the pulmonary vascular system using computerassisted semi-automated morphometry (NIS-BR software, Nikon, Champigny sur Marne, France): (1) wall thickness of muscular pulmonary arteries, (2) degree of microvascular muscularization, and (3) degree of pulmonary capillary density.

Wall thickness of muscular pulmonary arteries: We selected three muscular pulmonary arteries per slide from each sample ( 9 arteries per patient), with a diameter between 100 and $350 \mu \mathrm{m}$, adjacent to a bronchiole. On slides colored with orcein, we outlined the different arterial wall layers (Figure 1). We then measured the areas of arterial lumen, intima and media of each artery. These measurements were expressed as percentage of the total artery area, limited by the external elastic lamina.

Degree of microvascular muscularization: We analyzed the muscularization of the microvessels (arterioles and venules) on slides stained by anti-actin antibodies. We selected ten microvessels per slide (thirty per patient), with a diameter inferior to 80 
$\mu \mathrm{m}$, lacking an adjacent airway, located within an alveolar intersection. We applied the following semiquantitative score in order to assess the degree of microvascular muscularization on actin-stained pulmonary vessels (either arterioles or venules): (A) no remodelling (grade 0 , absence of muscle cells circumferentially), (B) partial remodelling (grade 1, circumferential muscle cells, but on a single layer), (C) important remodelling (grade 2, circumferential and thick muscle cells with several layers), (D) very important remodelling (grade 3, presence of multiple layers of smooth muscle cells, and partial or complete obliteration of arterial lumen). This score is a modified version of typical histologic vascular assessment scores used in $\mathrm{PH}$ research, mostly on animal models (13). Examples are given in Figure 2. A score was then calculated for each patient by averaging the scores of the thirty arteries.

Degree of pulmonary capillary density:

We analyzed the degree of pulmonary capillary density on slides immunohistochemically stained by anti-Erg antibodies. We randomly selected five fields per slide (fifteen per patient), including only alveolar walls (no larger arteries, no bronchioles), at x200 magnification. The number of endothelial nuclei within this area, as well as the area of the corresponding pulmonary parenchyma was counted/measured using computer-assisted semi-automated morphometry (NIS-BR software) (Figure 3A, 3D). A ratio between the number of brown stained nuclei (i.e. the number of endothelial cells, assumed to be mostly pulmonary capillary endothelial cells) and the parenchyma surface was then calculated in order to approximate the pulmonary capillary density.

As ERG expression can be down-regulated by inflammatory stimuli (14), and COPD is known to be an inflammatory disease; and as some studies suggest that diseased lung endothelium in PAH, as well as in chronically hypoxic mice, exhibit loss of ERG 
(15), we have stained 2 cases with an anti-CD31 and an anti-CD34 antibodies in order to compare them with ERG staining and to double-check the visual loss of capillaries (Figure 3). We used ERG-staining for the assessment of capillary density because of its singular characteristic to produce a nuclear staining pattern in endothelial cells. in a 3-dimensional capillary meshwork, only the counting of discrete nuclear units can reflect the true number of endothelial cells, as compared to broad ill-delimited cytoplasmic stainings, e.g. with anti-von-Willebrand-factor, anti-CD31, or anti-CD34.

$\underline{\text { Statistical analysis }}$

Statistical analysis was performed using GraphPadPrism software version 5 (GraphPadSoftware Inc., San Diego, CA, USA).

Continuous data are expressed as median (interquartile), and categorical data are presented as count and proportions. Univariate analyses were made by KruskalWallis test and Dunn's post-test and $x^{2}$ test. A p-value $<0.05$ was considered statistically significant.

Correlation coefficients in univariate analysis were estimated using a Spearman test.

\section{Results}

\section{$\underline{\text { Characteristics of the patients }}$}

During the study period, 200 COPD patients underwent lung transplantation in our department. We excluded 5 patients with missing pulmonary hemodynamic data and 56 patients with $\mathrm{Pw}>15 \mathrm{~mm} \mathrm{Hg}$. Among the 139 remaining patients, 10 presented with severe PH-COPD. All had a mPAP $\geq 35 \mathrm{~mm} \mathrm{Hg}$. From the remaining 129 patients, we randomly selected a group of 10 patients with moderate $\mathrm{PH}$ and a group of 10 patients without $\mathrm{PH}$ (Figure 4).

Thus, 30 patients form the basis of this study. The demographic characteristics of the 
3 groups of patients are shown in Table 1.

Among the 30 patients, all had severe dyspnea, with mMRC dyspnea grade 4 in $71 \%$ of cases, the majority (87\%) received long-term oxygen therapy, and one third were under home non-invasive ventilation.

Five patients had another condition that could contribute to aggravation of $\mathrm{PH}$ : two patients had had a previous surgical volume reduction, three patients had sleep apnea syndrome (non severe or under nocturnal continuous positive airway pressure), and one patient in the severe $\mathrm{PH}$ group had received isomeride, but for only two months. No patients had left heart disease. Four patients had hepatic steatosis, but none had portal hypertension. The 3 groups did not differ with regard to their clinical characteristics.

The results of pulmonary function tests in each group are shown in Table 2. Overall, the patients had severe airflow limitation with median $\mathrm{FEV}_{1}$ at $18 \%$ predicted $(15 \%$ $23 \%)$ and marked thoracic distension with median TLC at $135 \%$ predicted (125\%$157 \%$ ) and median RV at $296 \%$ predicted (270\%-344\%). Only two patients, both from the severe $\mathrm{PH}$ group, had a $\mathrm{FEV}_{1}$ over $30 \%$ predicted ( $41 \%$ and $65 \%$, respectively). Overall, the 30 patients had also a profound impairment of DLCO [19\% predicted (10\%-24\%)]. The severe PH group tended to have a lower DLCO but it did not reach statistical significance.

Only three variables were statistically different between the 3 groups: patients with severe $\mathrm{PH}$ had a significantly higher $\mathrm{FEV}_{1} / \mathrm{FVC}$ ratio $(\mathrm{p}=0.049)$, a lower TLC $(p=0.008)$ and a lower $\mathrm{PaO}_{2}$ on room air $(p=0.016)$ than patients without $\mathrm{PH}$.

The hemodynamic data are given in Table 3. The median Pw was $12.5 \mathrm{~mm} \mathrm{Hg} \mathrm{(11-}$ $14.25 \mathrm{~mm} \mathrm{Hg}$ ). Cardiac output was preserved with median output at $5.7 \mathrm{~L} / \mathrm{min}$ (4.6- 
6.6 L/min) and median cardiac index at $3.2 \mathrm{~L} / \mathrm{min} / \mathrm{m}^{2}\left(2.72-4.01 \mathrm{~L} / \mathrm{min} / \mathrm{m}^{2}\right)$. Cardiac index was $>2 \mathrm{~L} / \mathrm{min} / \mathrm{m}^{2}$ in all patients.

\section{$\underline{\text { Histological analysis }}$}

Before the quantitative analysis, all slides were analyzed independently by two experienced pathologists (PD, CD). Both agreed on several points: emphysema lesions were present in all patients, no plexiform lesions were observed, and only a few patients had significant arterial inflammation without apparent difference between the 3 groups.

The measurements performed on medium-size arteries, arterioles and capillaries are summarized in Table 4.

No difference in the diameters of the medium-size arteries between the 3 groups was found. There was also no difference in the medial area $(p=0.091)$ and in the available lumen area ( $p=0.107)$ between the 3 groups. The intimal area was significantly lower in the moderate $\mathrm{PH}$ than in the no- $\mathrm{PH}$ group (15.9\% versus $24.5 \%$, $p=0.023)$. We did not observe any difference in intimal area of medium size arteries between the moderate $\mathrm{PH}$ and the severe $\mathrm{PH}$ group.

The microvessels remodelling scores of the three groups are given in Figure 5. The microvessels were more muscularized in the severe $\mathrm{PH}$ group, as attested by a significantly higher remodelling score in this group than in the moderate $\mathrm{PH}$ group (1.284 versus $0.867, p=0.0045)$. The difference was not significant between the no$\mathrm{PH}$ group and the severe $\mathrm{PH}$ group.

The analysis of the capillary network density is detailed in Figure 6. The density of the capillary network was lower in the severe $\mathrm{PH}$ group than in the moderate $\mathrm{PH}$ group $\left(0.00235 / \mu \mathrm{m}^{2}\right.$ versus $\left.0.00526 / \mu \mathrm{m}^{2}, \mathrm{p}=0.0049\right)$. In the 2 patients described in Figure 3, we found that the intensity of ERG staining was comparable to that of CD31 
and CD 34 staining in each case. This observation suggests that the low level of ERG staining in our severe $\mathrm{PH}$ group is related to a loss of capillary network.

We did not find any correlation between microvessel remodelling and capillary loss (Spearman r -0,3217, IC95\% -0.6181 to $0.05483, p=0,0830$ ).

\section{Discussion}

The salient results of our study based on a morphometric analysis of explanted lungs are the following: 1 ) the group of patients with severe $\mathrm{PH}-\mathrm{COPD}$ is characterized by a higher degree of vascular remodelling of the pulmonary microvessels (arterioles and/or venules) than that observed in the moderate $\mathrm{PH}$ group; 2) the severe $\mathrm{PH}$ group presents with a lower capillary density than the moderate $\mathrm{PH}$ group; 3) in no instances, we found aspects of plexiform lesions of pulmonary vessels such as those described in PAH (group $1 \mathrm{PH})$.

A particular phenotype of COPD patients characterized by the presence of severe $\mathrm{PH}$ has been identified more than ten years ago by several investigators $(7,8)$ using different methodological approaches. This entity, concerning a minority of COPD patients, has been recognized by the Nice WHO symposium on PH in 2013 (10). Besides the presence of a high level mPAP, the main clinical features of patients with this phenotype are marked exercise limitation, profound hypoxemia, low DLCO, and poor prognosis (8), sometimes contrasting in the most typical cases with a moderate airflow limitation. Hitherto, there is no evidence that treatment with antiproliferative drugs active on the pulmonary vasculature provides a benefit and it is therefore recommended that such patients should be referred to a $\mathrm{PH}$ expert center $(10,16)$. They should also be considered for lung transplantation if they satisfy the selection criteria (17). 
The patients of the present study shared some of the previously described characteristics of severe $\mathrm{PH}-\mathrm{COPD}$ patients. Our patients from the severe $\mathrm{PH}$ group indeed had a more profound hypoxemia than the 2 other groups of patients but despite the fact that 2 patients from this group had a FEV1 above $30 \%$ predicted, no statistically significant difference in median $\mathrm{FEV}_{1}$ and DLCO between the 3 groups was detected. This fact could be due to the limited number of studied patients and also to a selection bias since we limited our study population to those who underwent lung transplantation.

It is well known that structural changes in pulmonary circulation are associated with COPD $(11,18-24)$. Most authors have described a remodelling of the pulmonary vasculature with intimal thickening in muscular pulmonary arteries and arterioles as well as muscularization of pulmonary arterioles. However, the studies focusing on this topic are heterogeneous, the patients varying from one study to another in terms of severity of airflow obstruction and in terms of presence and severity of $\mathrm{PH}$. In particular, very few studies provide an analysis stratified according to the severity of $\mathrm{PH}(11,21)$. The specific role of smoking is difficult to interpret since it has been shown that COPD patients and smokers without COPD may present with similar intimal abnormalities (18).

Data concerning the histological lesions of the pulmonary vasculature in the setting of severe PH-COPD are very scarce. As we did, Carlsen and coworkers have retrospectively analyzed the pulmonary vascular lesions (muscular pulmonary arteries and arterioles) of lungs explanted during a transplantation in 10 patients with severe $\mathrm{PH}-\mathrm{COPD}$ and compared them to a group of patients without $\mathrm{PH}$ and to a group of patients with moderate $\mathrm{PH}$ (11). Using a semi-quantitative evaluation with a scoring system based on the Heath and Edwards classification of hypertensive 
pulmonary vascular disease (25), they found that the extent of pulmonary vascular lesions in COPD correlated with the severity of $\mathrm{PH}$. In the particular case of the severe $\mathrm{PH}$ group, medial hypertrophy and concentric laminar intimal fibrosis was observed as well as in some cases, pathologic changes characteristic of idiopathic $\mathrm{PAH}$, including plexiform lesions, pulmonary hemosiderosis and angiomatoid lesions. Wright et al. who compared the structure of muscular pulmonary arteries of COPD patients stratified according to their level of mPAP, including a group with severe $\mathrm{PH}$, found alterations in arterial structure as compared with control population but these did not correlate with the severity of $\mathrm{PH}$ (21). The authors did neither focus on microvessels nor on capillaries.

Our morphometric approach allowed us a more precise evaluation of the lesions than that by Carlsen and coworkers. In contrast with the latter study (11), we did not detect a difference of medial and intimal lesions of medium-size (muscular) pulmonary arteries according to the severity of $\mathrm{PH}$. The main differences between the 3 groups were observed at the level of arterioles and capillaries, more pronounced muscularization of the arterioles and lower capillary density appearing to be the hallmark of the severe PH-COPD group. In no instances, lesions similar to those seen in PAH were observed arguing against the hypothesis that PH-COPD could in fact represent the coincidental association of a frequent disease (COPD) and a rare disease (group $1 \mathrm{PH}$ ).

We did not find any correlation between microvessel remodelling and capillary loss. This result can be explained by the limited number of patients. In fact, the study was not designed for this kind of statistical approach. It can also mean that these two mechanisms are involved in a different way in the genesis of pulmonary hypertension. 
Admittedly, our results are less unequivocal with regard to the no-PH group. Obviously, our findings show that the absence of clinical relevant $\mathrm{PH}$ is not equivalent to a normal/non-diseased pulmonary vasculature. In our view, this is not surprising, since the threshold for $\mathrm{PH}$-relevant pulmonary precapillary obstruction $(>25 \mathrm{~mm} \mathrm{Hg}$ ) can be calculated with the distensibility model of Linehan and corresponds to 50 per cent of the vascular surface when a cardiac output of $5 \mathrm{~L} / \mathrm{min}$ is applied (26).

Therefore, it appears coherent that some of the no-PH group patients with pulmonary arterial pressures close to the cut-off value for $\mathrm{PH}$ will present with substantial vascular lesions (7 out 10 patients of this group had mPAP between 19 and $24 \mathrm{~mm}$ $\mathrm{Hg}$, which could be classified as borderline $\mathrm{PH}(27)$.

In this context, it is important to mention that when merging the no- $\mathrm{PH}$ and the moderate $\mathrm{PH}$ groups, the level of microvascular muscularization was significantly discriminative in comparison with the severe $\mathrm{PH}$ group $(0.967$ versus $1.284 ; \mathrm{p}=$ 0.0029).

However, the relatively small size of our 3 groups probably failed to accentuate a statistically significant difference between no-PH and moderate $\mathrm{PH}$ groups.

Our study has several limitations: 1) the study is retrospective; 2) the number of patients with severe PH-COPD is low, as was the case in the Danish study (11). It could have led to miss an important information; 3) since the study was designed in 2013, we used the definition of severe PH-COPD proposed by the $5^{\text {th }}$ world symposium on $\mathrm{PH}$ patients instead of the slightly modified definition given by the latest (2015) European Respiratory Society/European Society of Cardiology guidelines for the diagnosis and treatment of $\mathrm{PH}$ (mPAP $>35 \mathrm{~mm} \mathrm{Hg}$ or $\mathrm{mPAP} \geq 25$ $\mathrm{mm} \mathrm{Hg}$ in the presence of a low cardiac output (cardiac index $<2.5 \mathrm{~L} / \mathrm{min} / \mathrm{m}^{2}$, not explained by other causes)(28); 4) the study included only lungs from patients who 
underwent lung transplantation and hence who had end-stage disease, in most cases concomitant with substantial destruction of the lung parenchyma. Our findings may not be applicable to all cases of PH-COPD. Despite these limitations, the strengths of our study should be underlined: it is one of the rare studies providing morphometric data on the histologic lesions associated with various forms of $\mathrm{PH}$ in COPD; it adds further information on the involvement of the pulmonary arterioles and on the capillary bed in COPD.

In summary, our study, which is based on morphometric analysis of the pulmonary vasculature of lung explants from patients who underwent lung transplantation for COPD, demonstrates that the morphological correlate or hallmark of severe $\mathrm{PH}$ COPD, when compared with moderate PH-COPD, lies in the substantially increased muscularization of pulmonary microvessels (arterioles and/or venules), as well as in the lower capillary density. Importantly, no significant differences were observed in the muscular-type pulmonary arteries, which are relevant in $\mathrm{PAH}$ (group 1) and no typical PAH lesions, such as plexiform lesions or onion-skin lesions (concentric laminar intimal fibrosis) were detected, stressing at least the different morphological phenotype of severe $\mathrm{PH}-\mathrm{COPD}$ and $\mathrm{PAH}$. 


\section{Aknowledgements}

Guarantor statement: Hervé Mal takes responsibility for the content of the manuscript, including the data and analysis

Author contributions : HM, VB, PD had full access to all of the data in the study and take responsibility for the integrity of the data and the accuracy of the data analysis, including and especially any adverse effects. AG, CD performed the histological analysis with VB. GT, YC, GD, MH, DM and CG contributed substantially to the study design, data analysis and interpretation, and the writing of the manuscript.

Funding sources: none

Conflict of interest: none 


\section{References}

1. Simonneau G, Gatzoulis MA, Adatia I, Celermajer D, Denton C, Ghofrani A, et al. Updated clinical classification of pulmonary hypertension. J Am Coll Cardiol. 2013;62(25 Suppl):D34-41.

2. Weitzenblum E, Sautegeau A, Ehrhart M, Mammosser M, Hirth C, Roegel E. Prognostic value of pulmonary artery pressure in chronic obstructive pulmonary disease. Thorax. 1981;36:752-8.

3. Oswald-Mammosser M, Weitzenblum E, Quoix E, Moser G, Chaouat A, Charpentier $\mathrm{C}$, et al. Prognostic factors in COPD patients receiving long-term oxygen therapy. Importance of pulmonary artery pressure. Chest. 1995;107(5):1193-8.

4. Andersen $\mathrm{KH}$, Iversen $\mathrm{M}$, Kjaergaard J, Mortensen J, Nielsen-Kudsk JE, Bendstrup E, et al. Prevalence, predictors, and survival in pulmonary hypertension related to end-stage chronic obstructive pulmonary disease. J Heart Lung Transplant. 2012;31(4):373-80.

5. Weitzenblum E, Chaouat A. Pulmonary hypertension due to chronic hypoxic lung disease. Peacock AJ, Rubin LJ, editors. London: Arnold; 2004. Pages 374-86 p.

6. Barbera JA, Peinado VI, Santos S. Pulmonary hypertension in chronic obstructive pulmonary disease. Eur Respir J. 2003;21(5):892-905.

7. Thabut G, Dauriat G, Stern JB, Logeart D, Levy A, Marrash-Chahla R, et al. Pulmonary hemodynamics in advanced COPD candidates for lung volume reduction surgery or lung transplantation. Chest. 2005;127(5):1531-6.

8. Chaouat A, Bugnet AS, Kadaoui N, Schott R, Enache I, Ducolone A, et al. Severe pulmonary hypertension and chronic obstructive pulmonary disease. Am J Respir Crit Care Med. 2005;172(2):189-94.

9. Nathan S, Hassoun PM. Pulmonary hypertension due to lung disease and/or hypoxia. Clin Chest Med. 2013;34:695-705.

10. Seeger W, Adir Y, Barbera JA, Champion H, Coghlan JG, Cottin V, et al. Pulmonary hypertension in chronic lung diseases. J Am Coll Cardiol. 2013;62(25 Suppl):D109-16.

11. Carlsen J, Hasseriis Andersen K, Boesgaard S, Iversen M, Steinbruchel D, Bogelund Andersen C. Pulmonary arterial lesions in explanted lungs after transplantation correlate with severity of pulmonary hypertension in chronic obstructive pulmonary disease. J Heart Lung Transplant. 2013;32(3):347-54.

12. Birdsey GM, Dryden NH, Amsellem V, Gebhardt F, Sahnan K, Haskard DO, et al. Transcription factor Erg regulates angiogenesis and endothelial apoptosis through VE-cadherin. Blood. 2008;111(7):3498-506.

13. Schermuly RT, Dony E, Ghofrani HA, Pullamsetti S, Savai R, Roth M, et al. Reversal of experimental pulmonary hypertension by PDGF inhibition. J Clin Invest. 2005; $115(10): 2811-21$.

14. Shah AV, Birdsey GM, Randi AM. Regulation of endothelial homeostasis, vascular development and angiogenesis by the transcription factor ERG. Vascular pharmacology. 2016;86:3-13.

15. Looney AP, Han R, Stawski L, Marden G, Iwamoto M, Trojanowska M. Synergistic Role of Endothelial ERG and FLI1 in Mediating Pulmonary Vascular Homeostasis. Am J Respir Cell Mol Biol. 2017;57(1):121-31.

16. Humbert M, Simonneau G. Vasodilators in patients with chronic obstructive pulmonary disease and pulmonary hypertension: not ready for prime time! Am J Respir Crit Care Med. 2010;181(3):202-3. 
17. Weill D, Benden C, Corris P, Dark JH, Duane Davis R, Keshavjee S, et al. A consensus document for the selection of lung transpalnt candidates: 2014-An update from the pulmonary transplantation councilof the International Society for Heart and Lung Transpalntation. Journal of Heart and Lung Transplantation. 2015;34:1-15.

18. Santos S, Peinado VI, Ramirez J, Melgosa T, Roca J, Rodriguez-Roisin R, et al. Characterization of pulmonary vascular remodelling in smokers and patients with mild COPD. Eur Respir J. 2002;19(4):632-8.

19. Peinado VI, Gomez FP, Barbera JA, Roman A, Angels Montero M, Ramirez J, et al. Pulmonary vascular abnormalities in chronic obstructive pulmonary disease undergoing lung transplant. J Heart Lung Transplant. 2013;32(12):1262-9.

20. Wright JL, Lawson L, Pare PD, Hooper RO, Peretz DI, Nelems JM, et al. The structure and function of the pulmonary vasculature in mild chronic obstructive pulmonary disease. The effect of oxygen and exercise. Am Rev Respir Dis. 1983;128(4):702-7.

21. Wright JL, Petty T, Thurlbeck WM. Analysis of the structure of the muscular pulmonary arteries in patients with pulmonary hypertension and COPD: National Institutes of Health nocturnal oxygen therapy trial. Lung. 1992;170(2):109-24.

22. Wilkinson $M$, Langhorne CA, Heath D, Barer GR, Howard P. A pathophysiological study of 10 cases of hypoxic cor pulmonale. The Quarterly journal of medicine. 1988;66(249):65-85.

23. Munoz-Esquerre M, Lopez-Sanchez M, Escobar I, Huertas D, Penin R, Molina-Molina M, et al. Systemic and Pulmonary Vascular Remodelling in Chronic Obstructive Pulmonary Disease. PLoS One. 2016;11(4):e0152987.

24. Hale KA, Niewoehner DE, Cosio MG. Morphologic changes in the muscular pulmonary arteries: relationship to cigarette smoking, airway disease, and emphysema. Am Rev Respir Dis. 1980;122(2):273-8.

25. Heath D, Edwards JE. The pathology of hypertensive pulmonary vascular disease; a description of six grades of structural changes in the pulmonary arteries with special reference to congenital cardiac septal defects. Circulation. 1958;18(4 Part 1):533-47.

26. Reeves JT, Linehan JH, Stenmark KR. Distensibility of the normal human lung circulation during exercise. Am J Physiol Lung Cell Mol Physiol. 2005;288(3):L41925.

27. Maron BA, Hess E, Maddox TM, Opotowsky AR, Tedford RJ, Lahm T, et al. Association of Borderline Pulmonary Hypertension With Mortality and Hospitalization in a Large Patient Cohort: Insights From the Veterans Affairs Clinical Assessment, Reporting, and Tracking Program. Circulation. 2016;133(13):1240-8.

28. Galie N, Humbert M, Vachiery JL, Gibbs S, Lang I, Torbicki A, et al. 2015 ESC/ERS Guidelines for the diagnosis and treatment of pulmonary hypertension: The Joint Task Force for the Diagnosis and Treatment of Pulmonary Hypertension of the European Society of Cardiology (ESC) and the European Respiratory Society (ERS): Endorsed by: Association for European Paediatric and Congenital Cardiology (AEPC), International Society for Heart and Lung Transplantation (ISHLT). Eur Respir J. 2015;46(4):903-75. 
Table 1: Clinical characteristics of the patients

\begin{tabular}{|c|c|c|c|c|c|}
\hline Variables & $\begin{array}{c}\text { TOTAL } \\
n=30\end{array}$ & $\begin{array}{c}\text { NO-PH } \\
n=10\end{array}$ & $\begin{array}{c}\text { MODERATE } \\
\text { PH } \\
\mathrm{n}=10 \\
\end{array}$ & $\begin{array}{c}\text { SEVERE PH } \\
n=10\end{array}$ & P \# \\
\hline Male sex, n (\%) & $18(60 \%)$ & $5(45 \%)$ & $5(45 \%)$ & $8(73 \%)$ & 0.28 \\
\hline Age, years (IQR) & $58(51.5-59)$ & $58(48.8-58)$ & $58.5(51.8-62)$ & $56(49.5-59)$ & $\begin{array}{c}0.43 \\
4\end{array}$ \\
\hline $\mathrm{BMI}, \mathrm{kg} / \mathrm{m}^{2}$ (IQR) & $\begin{array}{l}20.9(19.2- \\
25.1)\end{array}$ & $\begin{array}{l}20.4(18.6- \\
22.2)\end{array}$ & $21.4(19.1-24.9)$ & $\begin{array}{l}22.8(19.3- \\
27.6)^{*}\end{array}$ & $\begin{array}{c}0.39 \\
3\end{array}$ \\
\hline AAT deficiency, n (\%) & $5(17 \%)$ & $2(20 \%)$ & $1(10 \%)$ & $2(20 \%)$ & $\begin{array}{c}0.78 \\
7\end{array}$ \\
\hline $\begin{array}{l}\text { Smoking history, PY, } \\
\text { (IQR) }\end{array}$ & $40(24-60)$ & $45(20-60)$ & $51(29-60)$ & $40(3-53)$ & $\begin{array}{c}0.46 \\
1\end{array}$ \\
\hline $\begin{array}{l}\text { Time between } \mathrm{RHC} \text { and } \\
\text { lung } \mathrm{Tx} \text {, months (IQR) }\end{array}$ & $10.5(7-13.5)$ & $8(5.5-13.75)$ & $9.5(7.75-14.25)$ & $12.5(6.5-15.5)$ & $\begin{array}{c}0.74 \\
5\end{array}$ \\
\hline LTOT, n (\%) & 27 (87\%) & $9(82 \%)$ & $8(73 \%)$ & $10(91 \%)$ & 0.33 \\
\hline Home NIV, n (\%) & $9(29 \%)$ & $1(9 \%)$ & $5(45 \%)$ & $3(27 \%)$ & 0.15 \\
\hline Tracheostomy, n (\%) & $6(19 \%)$ & $0 \%$ & $3(27 \%)$ & $3(27 \%)$ & 0.15 \\
\hline Bilateral lung Tx, n (\%) & $10(32 \%)$ & $4(36 \%)$ & $3(27 \%)$ & $3(37 \%)$ & 0.86 \\
\hline $\begin{array}{l}\text { Dyspnea } \\
\text { mMRC 1, n (\%) } \\
\text { mMRC 2, n (\%) } \\
\text { mMRC 3, n (\%) } \\
\text { mMRC 4, n (\%) }\end{array}$ & $\begin{array}{c}1(3 \%) \\
2(6 \%) \\
5(16 \%) \\
22(71 \%) \\
\end{array}$ & $\begin{array}{c}0 \% \\
0 \% \\
3(27 \%) \\
7(64 \%) \\
\end{array}$ & $\begin{array}{c}1(9 \%) \\
0 \% \\
1(9 \%) \\
8(73 \%) \\
\end{array}$ & $\begin{array}{c}0 \% \\
2(18 \%) \\
1(9 \%) \\
7(64 \%) \\
\end{array}$ & 0.26 \\
\hline Hemoglobin, g/dL (IQR) & $\begin{array}{c}12.7(11.8- \\
14.2) \\
\end{array}$ & $\begin{array}{c}13.5(12.4- \\
15)^{\star \star}\end{array}$ & $12.9(12.6-14.3)$ & $11.7(10.6-13.1)$ & $\begin{array}{c}0.07 \\
4\end{array}$ \\
\hline $\begin{array}{l}\text { Associated cause of } \mathrm{PH}, \mathrm{n} \\
(\%)\end{array}$ & $5(16 \%)$ & 0 & $1(9 \%)$ & $4(36 \%)$ & 0.79 \\
\hline $\begin{array}{l}\text { Previous VTED, n (\%) } \\
\text { Previous LVRS, n (\%) } \\
\text { PoH, n (\%) } \\
\text { OSA, n (\%) } \\
\text { Drug-induced PH, n (\%) } \\
\text { HIV infection, n (\%) } \\
\text { LHF, n (\%) }\end{array}$ & $\begin{array}{c}0 \\
2(6 \%) \\
0 \\
3(10 \%) \\
1(3 \%) \$ \\
0 \\
0\end{array}$ & $\begin{array}{l}0 \\
0 \\
0 \\
0 \\
0 \\
0 \\
0\end{array}$ & $\begin{array}{c}0 \\
1(9 \%) \\
0 \\
0 \\
0 \\
0 \\
0\end{array}$ & $\begin{array}{c}0 \\
1(9 \%) \\
0 \\
3(27 \%) \\
1(9 \%) \$ \\
0 \\
0\end{array}$ & $\begin{array}{l}- \\
0.58 \\
- \\
0.34 \\
0.36 \\
- \\
-\end{array}$ \\
\hline
\end{tabular}

\section{Abbreviations:}

$\mathrm{PH}$ : pulmonary hypertension; BMI: body mass index; AAT: alpha-1 antitrypsin; RHC: right heart catheterization; PY: pack-years; LTOT: long-term oxygen therapy; NIV: non-invasive ventilation; Tx: transplantation; mMRC: modified medical research council dyspnea scale; VTED: venous thromboembolic disease; LVRS: lung volume reduction surgery; PoH: portal hypertension; OSA: obstructive sleep apnea; HIV: human immunodeficiency virus, LHF: left heart failure; IQR: interquartile range.

The continuous variables are presented in median and IQR (Q1-Q3).

\# Kruskal-Wallis test with Dunn post test

*1 missing data

** 2 missing data

$\$$ isomeride taken for 2 months 
Table 2: Pulmonary function test characteristics of the patients

\begin{tabular}{|c|c|c|c|c|c|}
\hline Variables & $\begin{array}{c}\text { TOTAL } \\
\mathrm{n}=30 \\
\end{array}$ & $\begin{array}{c}\text { NO-PH } \\
n=10\end{array}$ & $\begin{array}{c}\text { MODERATE PH } \\
\mathrm{n}=10 \\
\end{array}$ & $\begin{array}{c}\text { SEVERE PH } \\
n=10\end{array}$ & P \# \\
\hline $\mathrm{FEV}_{1}, \mathrm{~L}$ & $0.525(0.390-0.640)$ & $\begin{array}{c}0.550(0.368- \\
0.783)\end{array}$ & $0.525(0.453-0.593)$ & $0.510(0.390-0.850)$ & 0.9607 \\
\hline $\mathrm{FEV}_{1}, \%$ pred & $18(15-23)$ & $21(17-23)$ & $18(16-20)$ & $15(14-29)^{*}$ & 0.285 \\
\hline FCV, L & $1.390(0.980-2.190)$ & $\begin{array}{c}1.725(1.098- \\
2.920) \\
\end{array}$ & $\begin{array}{c}1.475(0.933- \\
1.948)^{\star *}\end{array}$ & $1.060(0.925-2.225)^{\star}$ & 0.5057 \\
\hline FVC, \% pred & $39(29-64)$ & $58(36-67)$ & $39(31-51)$ & $28(23-57)^{\star *}$ & 0.078 \\
\hline $\mathrm{FEV}_{1} / \mathrm{FVC}, \%$ & $37(29-48.5)$ & $29.5(27.8-35.8)$ & $37(29.5-49.5)^{*}$ & 43 (38.3-53.3) & 0.049 \\
\hline TLC, L & $8.230(6.930-9.200)$ & $\begin{array}{c}8.750(6.915- \\
9.695) \\
\end{array}$ & $8.100(7.115-9.530)^{*}$ & $\begin{array}{c}7.845(6.745- \\
8.583)^{\star *}\end{array}$ & 0.4147 \\
\hline TLC, \% pred & $135(125-157)$ & $151(144-161)$ & $139(121-165)$ & $126(103-135)^{\star}$ & 0.008 \\
\hline$R V, L$ & $5.780(5.020-6.650)$ & $\begin{array}{c}6.140(5.303- \\
6.875)\end{array}$ & $5.600(3.570-6.705)^{*}$ & $\begin{array}{c}5.550(3.458- \\
6.498)^{\star *}\end{array}$ & 0.40 \\
\hline $\mathrm{RV}, \%$ pred & $296(270-344)$ & $305(287-360)$ & $313(271-377)^{\star *}$ & $275(158-293)^{\star \star}$ & 0.066 \\
\hline RV/TLC, \% & $75(66-77)$ & $75(66-79)$ & $75(71-78)^{*}$ & $71(53-78)^{\star \star}$ & 0.516 \\
\hline $\mathrm{D}_{\mathrm{LCO}}, \%$ pred & $19(10-24)$ & $16(10-21)^{\star \star}$ & $21(18-27)^{* \star}$ & $13(10-32)^{* *}$ & 0.269 \\
\hline $\mathrm{PaO}_{2}, \mathrm{~mm} \mathrm{Hg}$ & $54(48-61)$ & $59(52-73)^{\star \star \star}$ & $60(49-63)^{* *}$ & $42(33-50)^{\star *}$ & 0.016 \\
\hline $\mathrm{PaCO}_{2} \mathrm{~mm} \mathrm{Hg}$ & $47(41-56)$ & $46(45-55)^{\star * \star}$ & $48(41-56)^{\star *}$ & $45(34-59)^{\star * \star}$ & 0.779 \\
\hline 6' WT, m & $180(130-261)$ & $228(145-297)$ & $176(151.5-348)^{*}$ & $146.5(112.5-204)$ & 0.3993 \\
\hline 6' WT, \% pred & $33(23-49)$ & $37(25-46)$ & $32(27-59)$ & $23(17-49)$ & 0.735 \\
\hline 6'WT $\Delta \mathrm{SpO} 2, \%$ & $6.5(4.3-10.5)$ & $6(3.8-7.5)$ & $5(3-11)^{\star \star *}$ & $11(6-17)^{\star \star \star}$ & 0.0635 \\
\hline
\end{tabular}

Data are expressed as median (interquartile range)In some cases, the high severity of the patients prevented the data collection ( ${ }^{*}: 1$ missing data; ${ }^{* *}: 2$ missing data; ${ }^{* * *}: 3$ missing data).

\section{Abbreviations:}

$\mathrm{PH}$ : pulmonary hypertension; $\mathrm{FEV}_{1}$ : maximum expiratory volume in 1 second; FVC: forced vital capacity; TLC: total lung capacity; RV: residual volume; $\mathrm{D}_{\mathrm{LCO}}$ : diffusing capacity for carbon monoxide; $\mathrm{PaO}_{2}: \mathrm{O}_{2}$ arterial pressure on room air; $\mathrm{PaCO}_{2}: \mathrm{CO}_{2}$ arterial pressure on room air; 6' WT: 6-minute walk test; 6' WT $\Delta \mathrm{SpO}_{2}$ : Desaturation during the 6-minute walk test, pred: predicted. 
Table 3: Hemodynamic characteristics of the patients

\begin{tabular}{|l|c|c|c|c|c|}
\hline \multicolumn{1}{|c|}{ Variables } & $\begin{array}{c}\text { TOTAL } \\
\mathbf{n = 3 0}\end{array}$ & $\begin{array}{c}\text { NO-PH } \\
\mathbf{n = 1 0}\end{array}$ & $\begin{array}{c}\text { MODERATE PH } \\
\mathbf{n = 1 0}\end{array}$ & $\begin{array}{c}\text { SEVERE PH } \\
\mathbf{n = 1 0}\end{array}$ & P \# \\
\hline sPAP, $\mathrm{mm} \mathrm{Hg}$ & $40.5(34.7-51.3)$ & $31(28.5-35.8)$ & $39(36-41.8)$ & $57.8(50.8-61.8)$ & $<\mathbf{0 . 0 0 0 1}$ \\
\hline $\mathrm{dPAP}, \mathrm{mm} \mathrm{Hg}$ & $22(17-30)$ & $16(12.8-17.3)$ & $22(20-22.8)$ & $31(29.5-35)$ & $<\mathbf{0 . 0 0 0 1}$ \\
\hline $\mathrm{mPAP}, \mathrm{mm} \mathrm{Hg}$ & $27.2(22.8-36.8)$ & $20.7(18.5-23.6)$ & $27.2(26.2-29.2)$ & $39.3(36.4-45.8)$ & $<\mathbf{0 . 0 0 0 1}$ \\
\hline $\mathrm{PW}, \mathrm{mm} \mathrm{Hg}$ & $12.5(11-14.25)$ & $11.5(9.8-14)$ & $12.5(11-14)$ & $14(12-15)$ & 0.13 \\
\hline $\mathrm{CO}, \mathrm{L} / \mathrm{min}$ & $5.7(4.6-6.6)$ & $5.2(4.5-6.5)$ & $5.2(4.5-7.0)$ & $6.3(5.6-7.0)$ & 0.321 \\
\hline $\mathrm{Cl}, \mathrm{L} / \mathrm{min} / \mathrm{m}^{2}$ & $3.19(2.72-4.01)$ & $3.43(2.71-3.94)$ & $3.06(2.62-4.25)$ & $3.18(2.95-4.15)$ & 0.7362 \\
\hline $\mathrm{PVR}, \mathrm{WU}$ & $2.7(1.9-3.8)$ & $1.7(1.4-2.3)$ & $2.6(2.1-3.4)$ & $4.2(3.5-5.1)$ & $<\mathbf{0 . 0 0 0 1}$ \\
\hline $\mathrm{iPVR}, \mathrm{WU} / \mathrm{m}^{2}$ & $1.54(1.2-2.2)$ & $1.1(0.8-1.4)$ & $1.5(1.3-2.0)$ & $2.3(2-3.3)^{\star}$ & $\mathbf{0 . 0 0 0 4}$ \\
\hline
\end{tabular}

The continuous variables are presented as median (interquartile range)

\# The 3 groups were compared by Kruskal-Wallis test and Dunn post-test.

* 1 missing data

Abbreviations:

PH: Pulmonary hypertension; sPAP: systolic pulmonary arterial pressure; dPAP: diastolic pulmonary arterial pressure; mPAP: mean pulmonary arterial pressure; Pw: pulmonary artery wedge pressure; CO: cardiac output; $\mathrm{Cl}$ : cardiac Index; PVR: pulmonary vascular resistance; IPVR: indexed pulmonary vascular resistance; WU: Wood units; IQR: interquartile range. 
Table 4: Histological characteristics of the 3 groups

\begin{tabular}{|c|c|c|c|c|}
\hline & $\begin{array}{c}\text { No PH } \\
n=10\end{array}$ & $\begin{array}{c}\text { Moderate PH } \\
\mathrm{n}=10\end{array}$ & $\begin{array}{c}\text { Severe PH } \\
n=10\end{array}$ & $\mathrm{p}$ \\
\hline \multicolumn{5}{|l|}{ MEDIUM-SIZE ARTERIES } \\
\hline Diameter of artery, $\mu \mathrm{m}$ & $224(212-244)$ & $236(222-243)$ & $231(209-240)$ & 0.652 \\
\hline Intimal area, \% total artery area & $24.5(15.4-29.4)^{\star}$ & $15.9(12.7-19.4)$ & $17.7(14.6-20.7)$ & 0.023 \\
\hline Medial area, \% total artery area & $33.8(31.5-36.7)$ & $32.5(29.3-39.7)$ & $39.1(35.9-41.8)$ & 0.091 \\
\hline $\begin{array}{l}\text { Arterial lumen area, \% total artery } \\
\text { area }\end{array}$ & $41.7(30.6-48.8)$ & $53.4(41.6-56.2)$ & $43.6(38.8-47.7)$ & 0.107 \\
\hline \multicolumn{5}{|l|}{ MICROVESSELS } \\
\hline Microvessels muscularization score & $1.067(0.775-1.175)$ & $0.867(0.75-0.983)$ & $\begin{array}{c}1.284(1.075- \\
1.425)^{\#} \\
\end{array}$ & 0.0045 \\
\hline \multicolumn{5}{|l|}{ PULMONARY CAPILLARIES } \\
\hline Capillary density, $\mathrm{Erg}+\mathrm{cells} / \mu \mathrm{m}^{2}$ & $\begin{array}{c}0.00429(0.00290- \\
0.00499) \\
\end{array}$ & $\begin{array}{c}0.00526(0.00382- \\
0.00613)\end{array}$ & $\begin{array}{c}0.00235(0.00197- \\
0.0038)^{\#}\end{array}$ & 0.0049 \\
\hline
\end{tabular}

Total artery area is defined as area limited by external elastic lamina.

Data are presented as median (interquartile range)

$\mathrm{PH}$ : Pulmonary hypertension. The value of $p$ indicates the result of the comparison between the 3 groups by a Kruskal-Wallis test and Dunn's post-test.

${ }^{*} \mathrm{p}<0.05$ for group without $\mathrm{PH}$ versus moderate $\mathrm{PH}$.

$\# \mathrm{p}<0.01$ for comparison between moderate $\mathrm{PH}$ group and severe $\mathrm{PH}$ group. 


\section{Legends of figures:}

\section{Figure 1:}

Measurement performed on a muscular-type pulmonary artery. The average diameter is $240.09 \mu \mathrm{m}$. The NIS-BR software allows us to calculate the area of arterial lumen, the area delimited by the internal elastic lamina, and the area delimited by the external elastic lamina $(21831.79 \mu \mathrm{m} 2)$. Magnification x200.

\section{Figure 2:}

Microvessels after immunohistochemistry staining with an anti-Actin antibody. Here we distinguish four degrees of remodeling: (A) no remodelling (grade 0 , absence of muscle cells circumferentially), (B) partial remodelling (grade 1, circumferential muscle cells, but on a single layer), (C) important remodelling (grade 2, circumferential and thick muscle cells with several layers), (D) very important remodelling (grade 3, presence of multiple layers of smooth muscle cells, and partial or complete obliteration of arterial lumen). Magnification x400.

\section{Figure 3:}

Comparison of pulmonary capillary density in two patients by immunohistochemistry. One patient with low capillary density (upper line): rare nuclei staining with anti-ERG (A), and thin and irregular cytoplasmic staining with anti-CD31 (B) and anti-CD34 (C) antibodies. Another patient with high capillary density (bottom line): numerous nuclei staining with anti-ERG (D), and dense and uninterrupted cytoplasmic staining with anti-CD31 (E) and anti-CD34 (F) antibodies. Magnification x 200.

\section{Figure 4:}

Flow chart describing the process of selection of the 3 groups of 10 patients, from the cohort of 467 patients who underwent lung transplantation between March 1988 and June 2013.

Abbreviations: pts: patients, COPD: chronic obstructive pulmonary disease; Pw: pulmonary arterial wedge pressure; mPAP: mean pulmonary arterial pressure.

\section{Figure 5:}

Comparison of microvessel remodelling score between the three groups of patients. $\mathrm{PH}$ : Pulmonary hypertension. Comparisons between the 3 groups were made by a Kruskal-Wallis test and Dunn's post-test. PH: Pulmonary hypertension

${ }^{* *} p<0.01$

\section{Figure 6:}

Comparison of the histological parameter evaluating the density of the capillary network between the three groups of patients. ERG + / Surface parenchyma represents the ratio between the number of endothelial cell nuclei (ERG-labeled) and the corresponding pulmonary parenchyma surface, ie the density of pulmonary capillaries. Comparisons between the 3 groups were made by a Kruskal-Wallis test and Dunn's post-test. PH: Pulmonary hypertension

${ }^{* *} p<0.01$ 


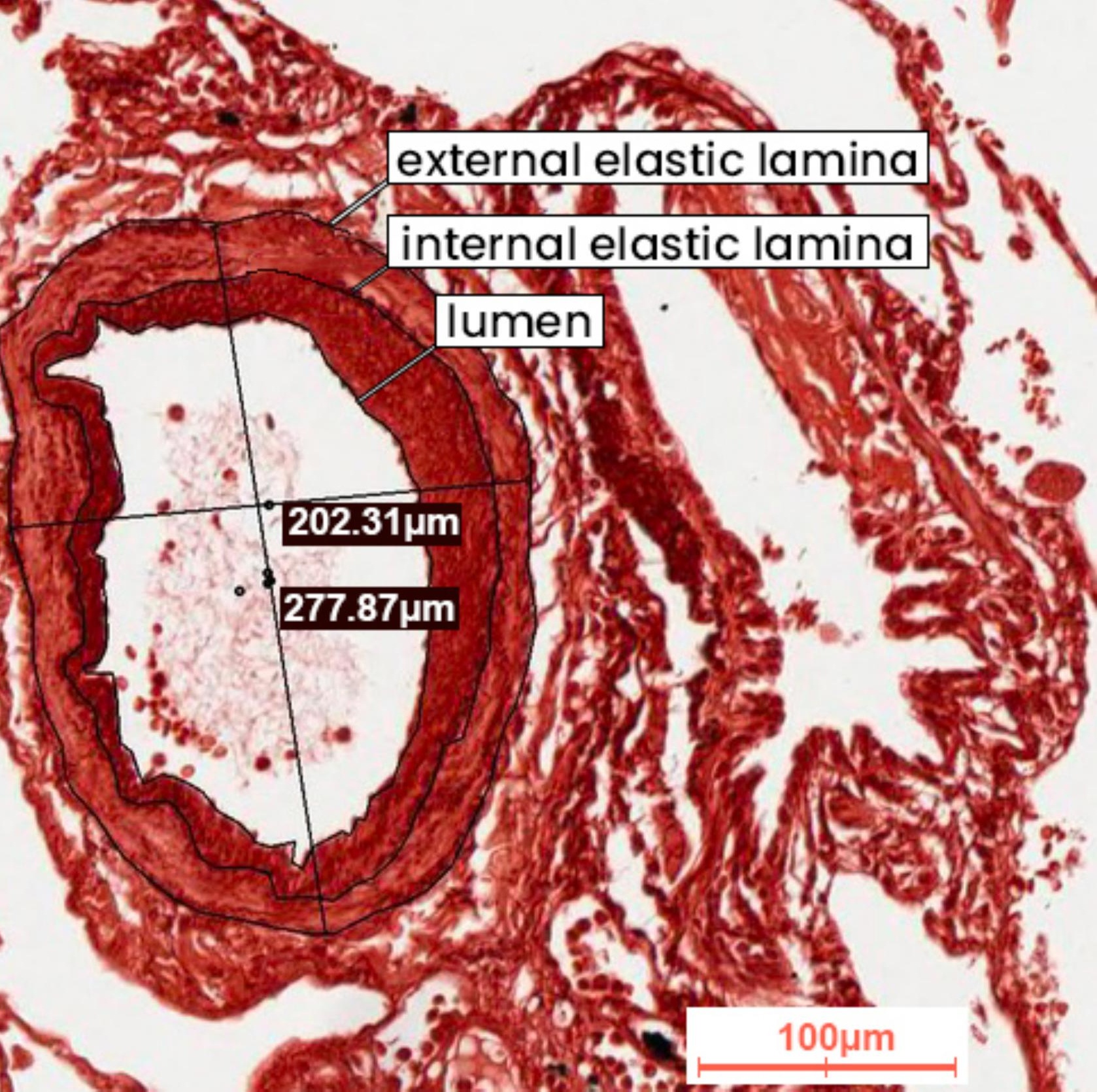




\section{for. $\mathbf{B}$} 4.

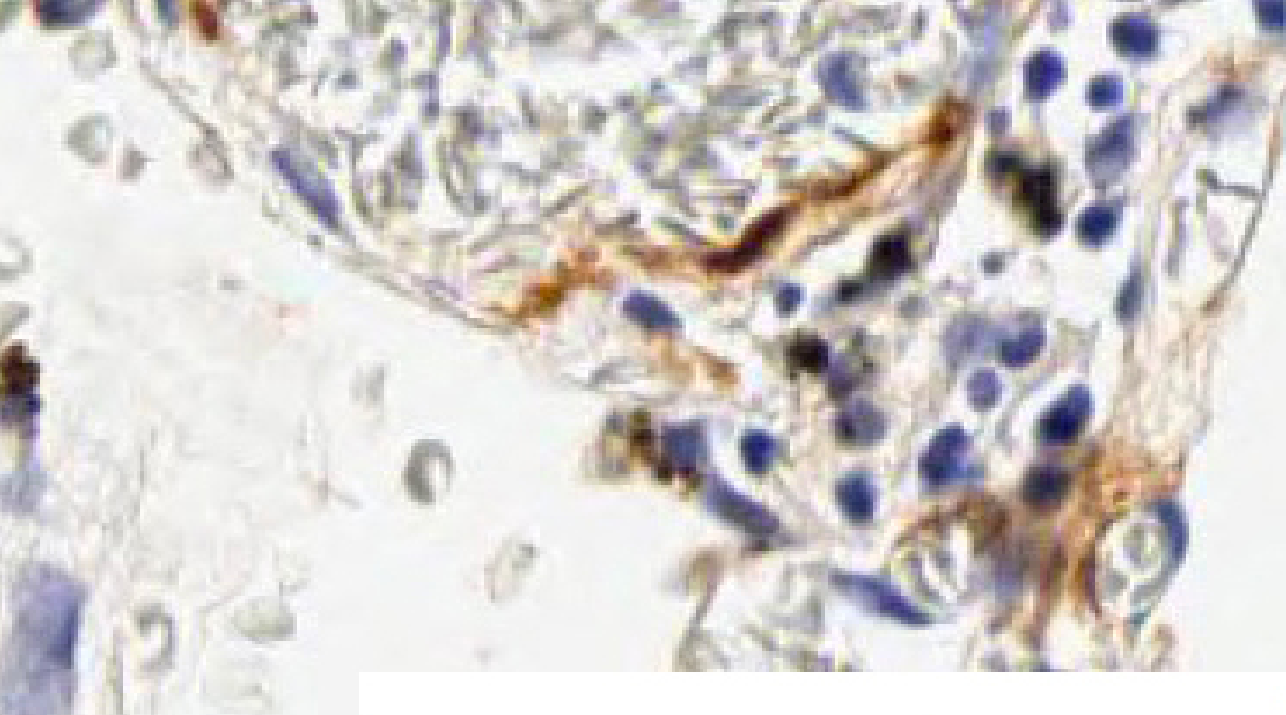

$100 \mu \mathrm{m}$

\section{C}
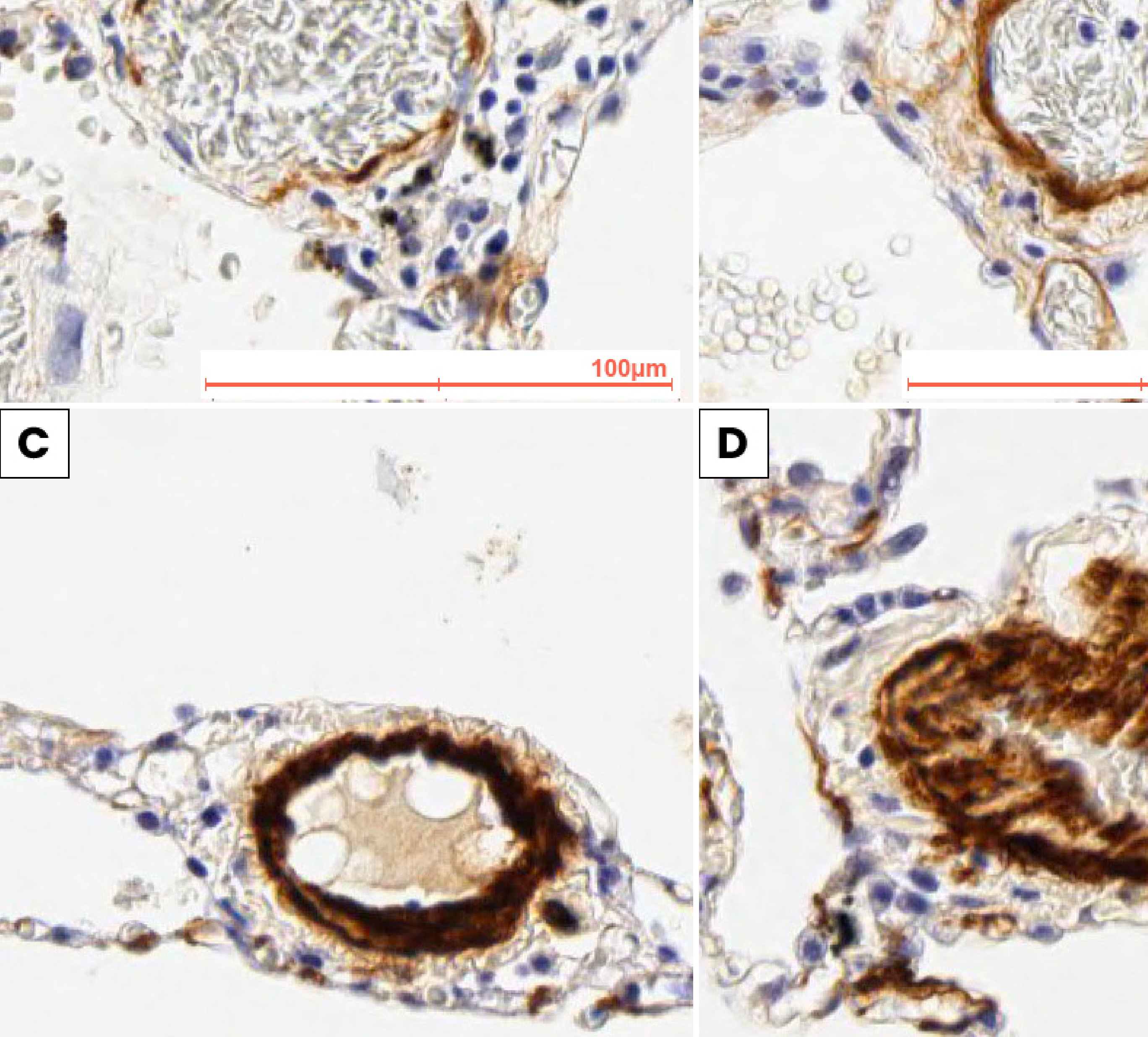

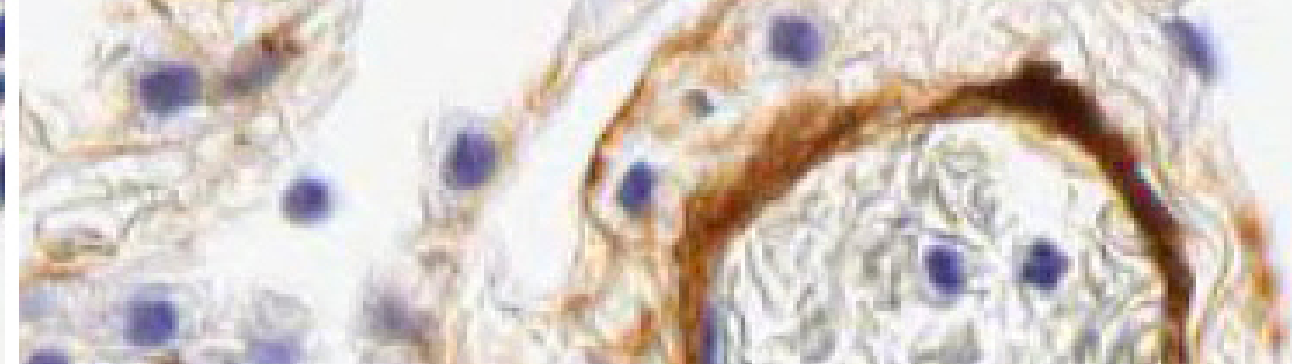

8 (2) sisis
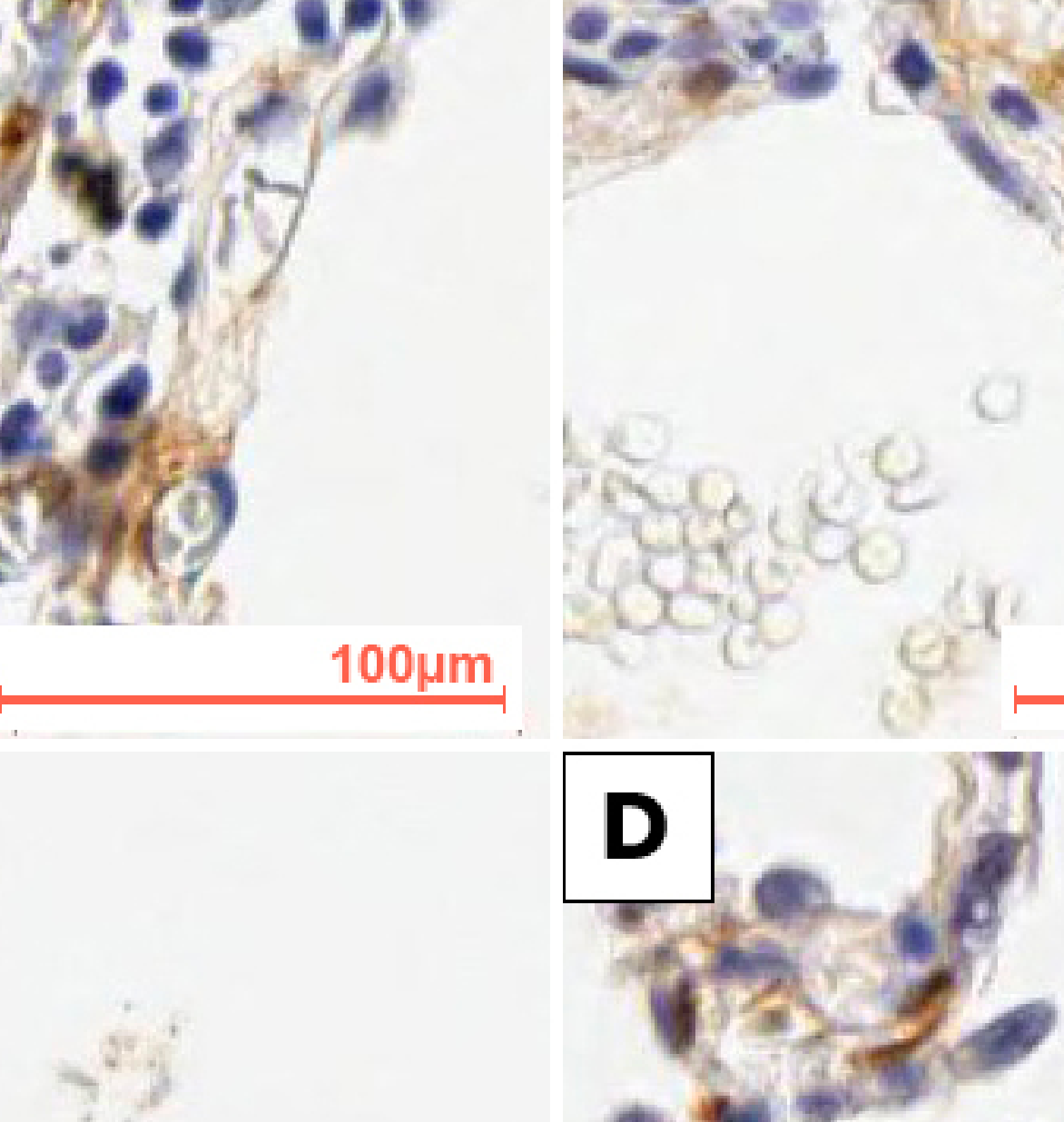


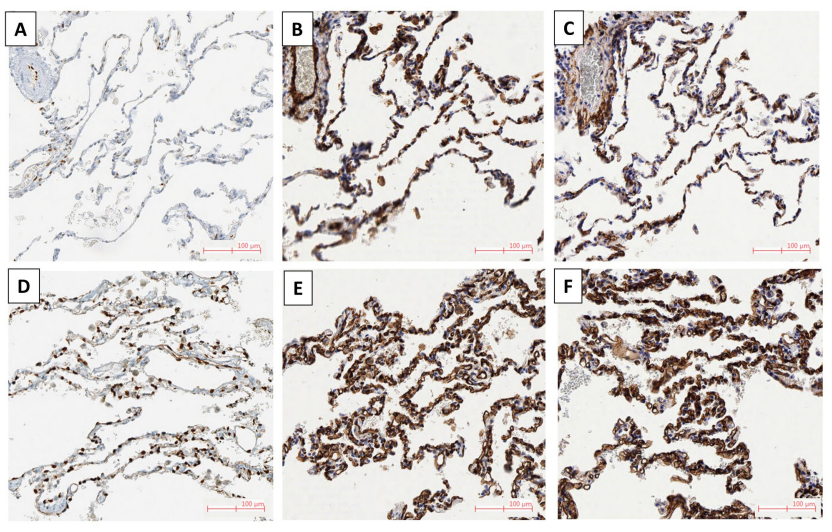


Transplanted patients $n=467$

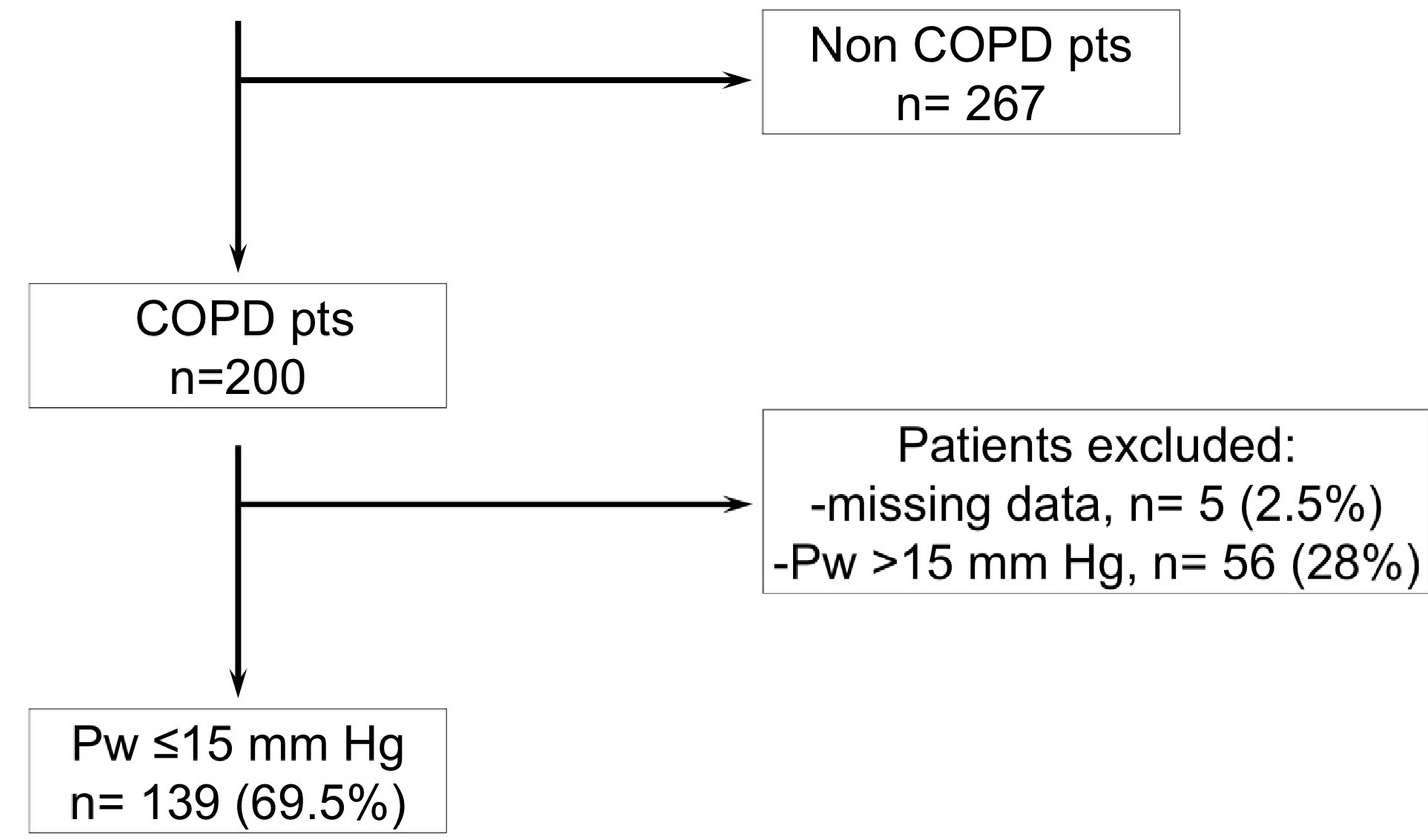

\section{$\mathrm{mPAP}<25 \mathrm{~mm} \mathrm{Hg}$}

$n=66(47.5 \%)$

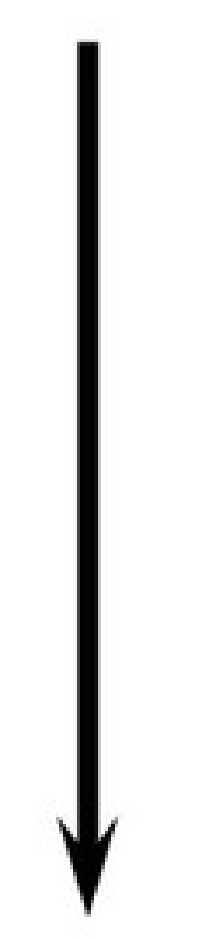

Matching and random selection

No $\mathrm{PH}$ group $(n=10)$

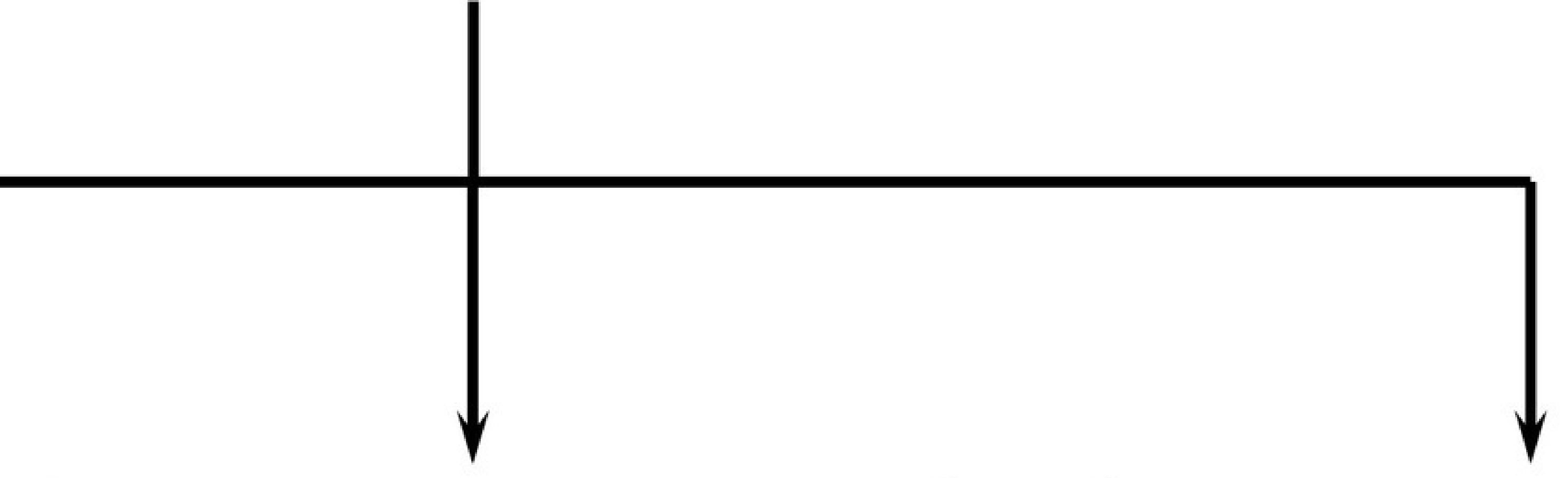

mPAP 25-34 mm Hg $n=63(45.3 \%)$

mPAP $\geq 35 \mathrm{~mm} \mathrm{Hg}$ $n=10(7.2 \%)$

$$
\downarrow
$$

Matching and random selection Moderate $\mathrm{PH}$ group $(n=10)$ 


\section{Microvessels muscularization}

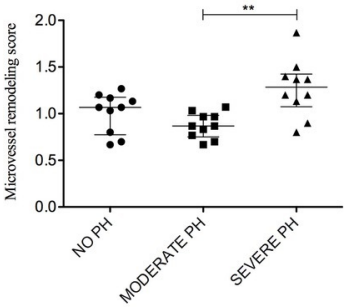




\section{Capillary density}

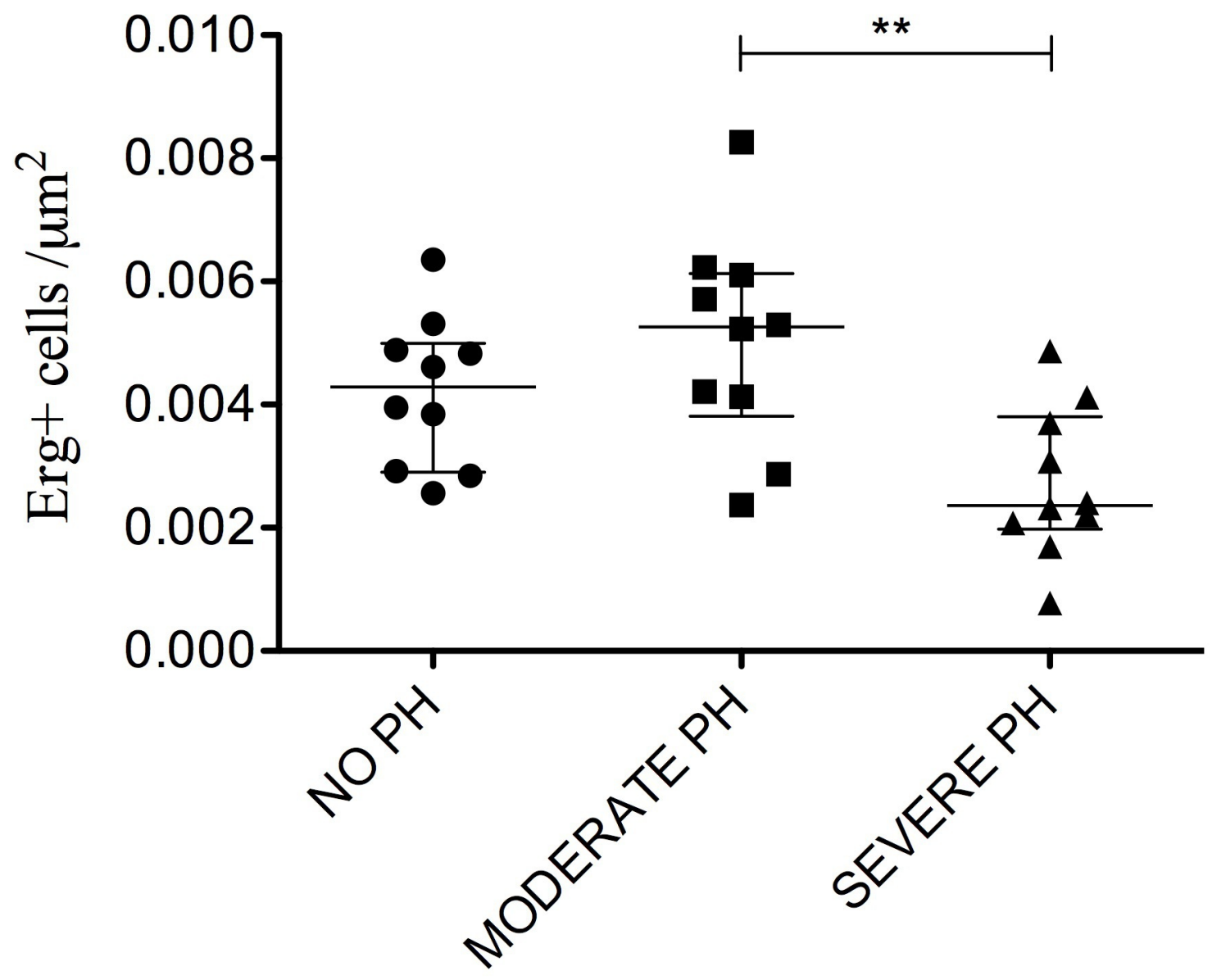

